\title{
Comparison of Epidural Steroid and Gabapentinin Lumbosacral Pain (Original Article)
}

\author{
Authors \\ Dr Vishal Moudgil, Dr Baljit Singh Bajwa
}

\begin{abstract}
Purpose: To evaluate whether an epidural steroid injection or gabapentin is a better treatment for lumbosacral radiculopathy in 150 patients.

Material and methods: A prospective intervention study was done on 150 patients with lumbosacral radicular pain secondary to herniated disc or spinal stenosis for less than four years in duration which may be associated with leg pain. Patients received either epidural steroid injection or gabapentin. The patient was evaluated according to the Oswestry disability index, which is a 10 question survey used to assess function in people with low back and/or leg pain.Pre and post treatment ODI was compared.The follow up was done monthly till 3 months.

Conclusions Although epidural steroid injection might provide greater benefit than gabapentin for some outcome measures, the differences are modest and are transient for most people.

Keywords: epidural, low back pain, gabapentin, disability, injection, spinal, Oswestry disability index
\end{abstract}

\section{Introduction}

Low back pain is one of the commonest problems with which a patient presents to the orthopaedician .The physical, socioeconomic, and psychological impact of low back pain is enormous. It has been one of the leading causes of the years lost to disability over the past several decades, ${ }^{\text {i }}$ with a lifetime prevalence that ranges between $50 \%$ and $90 \%$. ${ }^{\text {ii iii The patient spends lot }}$ of his money on this problem over half of which can be attributed to lost productivity..

The back pain classification is perhaps very important for distinction to make as it influences investigation and treatment decisions at all levels of care. ${ }^{\text {iv }}$ There are a number of ways to classify low back pain with no consensus that any one method is best. ${ }^{\mathrm{v}}$

\section{Classification Based on Etiology}

- Mechanical back pain (including nonspecific musculoskeletal Strains, herniated discs, compressed nerve roots, degenerative discs or joint disease, and broken vertebra)

- Non-mechanical back pain (tumors, inflammatory conditions such as spondyloarthritis, and infections), and

- Referred pain from internal organs (gallbladder disease, kidney stones, kidney infections, and aortic aneurysm, among others). .

Mechanical or musculoskeletal problems underlie most cases (around $90 \%$ or more), ${ }^{\mathrm{vi}}$ and of those, most (around 75\%) do not have a specific cause identified, but are thought to be due to muscle 
strain or injury to ligaments. Rarely, complaints of low back pain result from systemic or psychological problems, such as fibromyalgia and somatoform disorders.

\section{Classification based on the signs and symptoms:}

- Nonspecific: Diffuse pain that does not change in response to particular movements, and is localized to the lower back without radiating beyond the buttocks.

- Radicular: Pain that radiates down the leg below the knee, is located on one side (in the case of disc herniation), or is on both sides (in spinal stenosis), and changes in severity in response to certain positions or maneuvers is making up $7 \%$ of cases.

- Needing urgent or specialized attention: Pain that is accompanied by red flags such as trauma, fever, a history of cancer or significant muscle weakness may indicate a more serious underlying problem.

Classification on basis of symptoms by duration:

- acute: pain lasting less than six weeks

- sub-chronic (also known as sub-acute): , pain lasting six to twelve weeks

- chronic: more than twelve weeks

Management and prognosis may change based on the duration of symptoms. ${ }^{\text {vii }}$

Epidural steroid injections are the most commonly performed procedure for pain relief in the world, ${ }^{\text {viii }}$ being more commonly used and more effective for radicular pain than mechanical spine pain ${ }^{\text {ix }}$. Although mixed, most controlled studies have also found pharmacotherapy with gabapentinoids can be effective for lumbosacral radicular pain. ${ }^{\text {xi } x i i}$, xii

Numerous controlled trials have been performed to evaluate epidural steroid injections and drug treatment in people with low back pain, with review articles generally reporting modest effects. ${ }^{\text {xiv }}$ Yet for clinicians, the more relevant question is not whether a real treatment is better than a sham treatment, but which treatment is more effective. $^{\mathrm{xv}}$

Several small randomized open label studies have looked at epidural steroid injections compared with drug treatment. One study showed superiority for a single epidural steroid injection at one month but not later follow-up compared with tramadol and a muscle relaxant. ${ }^{\mathrm{xvi}} \mathrm{A}$ second study showed that a single caudal epidural steroid injection provided better pain relief than nonsteroidal anti-inflammatory drugs through three months. ${ }^{\text {xvii }}$ Neither study evaluated first line adjuvant treatments (such as gabapentin) as a comparison group. A more recent three armed multicenter study is performed in 169 patients with cervical radiculopathy. Over six months participants received nortriptyline and/or gabapentin plus physical therapies, up to three cervical epidural steroid injections, or combination treatment in which they received both injections and conservative care. They found that the combination group experienced a higher success rate at three months but not six months. ${ }^{\text {xviii }}$ Although these studies might simulate real life decisions facing clinicians, the fact that none are blinded precludes any conclusions regarding efficacy. We investigated a single epidural steroid injection compared with gabapentin in patients with lumbosacral radicular pain .

\section{Aims and Objectives}

To evaluate whether an epidural steroid injection or gabapentin is a better treatment for lumbosacral radiculopathy in 150 patients

\section{Material and methods}

A prospective interventional study was done to compare epidural steroid injection and gabapentin in lumbosacral pain.150 patients were enrolled in the study with following inclusion and exclusion criteria

Inclusion criteria Lumbosacral radicular pain based on history and physical exam (e.g. pain radiating into one or both lower extremities, 
sensory loss, muscle weakness, positive straight leg raising test etc.)

- Numerical Rating Scale leg pain score $>4$ (or if $3 / 10$, greater or equal to back pain)

- MRI evidence of spinal pathology consistent with symptoms

\section{Exclusion Criteria:}

- Untreated coagulopathy

- Previous spine surgery

- No MRI study

- Leg pain > 4 years duration

- Epidural steroid injection within past 3 years

- Cauda equina syndrome

- Previous failed trials with gabapentin or gabapentin

- Allergic reactions to gabapentin or pregabalin

- Referrals from surgery for diagnostic injections for surgical evaluation

- Serious medical or psychiatric that condition that might preclude optimal outcome or interfere with participation, such as the need for uninterrupted anticoagulation.

- Dementia, poorly controlled post-traumatic stress syndrome that might preclude an optimal response to treatment. Because our intention is to evaluate the relative effects of two commonly used treatments for radicular pain, we will exclude patients with neurogenic claudication from spinal stenosis who did not report lower leg pain that is, those who had only weakness or paresthesias

\section{Epidural Injections}

A orthopaedician or anaesthetist conducted all procedures using fluoroscopic guidance. The segmental level at which the injection will be administered is selected based on signs, symptoms, and radiological findings. For interlaminar injections, a Tuohy needle is inserted in or near the midline and advanced into the epidural space with image guidance in the anteroposterior and lateral views by using the loss of resistance technique. For transforaminal epidural steroid injections, a 22 gauge spinal needle is inserted coaxially into the upper part of the targeted foramina with the imagine intensifier positioned in an oblique plane. Correct placement is confirmed with the injection of contrast, which showed bilateral spread for all interlaminar injections and proximal epidural uptake for all transforaminal procedures. Once the consultant was satisfied with the pattern of contrast spread, a solution consisting of $60 \mathrm{mg}$ of depomethylprednisolone $+1 \mathrm{~mL}$ of $0.25 \%$ bupivacaine is administered. For those who received interlaminar injections, the injectate is diluted in normal saline to a volume of $4 \mathrm{~mL}$; in the transforaminal subgroup, the total volume administered is $3 \mathrm{~mL}$. Whereas some consultants routinely perform multilevel transforaminal injections, we limited our procedures to a single level to minimize risks because there are no controlled studies validating the use of more than one injection and because a well placed transforaminal epidural steroid injection generally spreads to multiple levels.

Pharmacotherapy Gabapentin, is a medication used as an anticonvulsant and analgesic.

Originally it was developed to treat epilepsy, and is currently used to relieve neuropathic pain and restless leg syndrome. It is recommended as a first line agent for the treatment of neuropathic pain arising from diabetic neuropathy, post-herpetic neuralgia, and central neuropathic pain. It is a structural analogue of the inhibitory neurotransmitter $\gamma$-aminobutyric acid (GABA).

Tramadol and non-steroidal anti-inflammatory drugs could be prescribed on an "as needed" basis as rescue medications (or opioids could be increased by up to $20 \%$ for those taking opioids), but no other co-interventions were permitted.

150 patients were enrolled the study, out of which 75patients received epidural injection of steroid and 75 patients received gabapentinin the form of 
$300 \mathrm{mg}$ tablets.After patient's entry to the orthopaedic OPD, every patient underwent thorough examination and patients with low back pain were assessed for eligibility.the patient was told about both treatment andafter assessing willingness and affordability the patient was allocated in either group.Informed consent was obtained from all the patients. The patients received their treatment and then follow up was done in out patient department after 1 month for 3 months. The patient was evaluated according to the Oswestry disability index, which is a 10 question survey used to assess function in people with low back and/or leg pain.Pre and post treatment ODI was compared. In those individuals who experienced a positive outcome at one month, the final follow-up occurred at three months. In these individuals, in addition to rescue medications, the study was titrated upwards. For ethical reasons, those with a negative outcome at one month left the study .

\section{Observation and Results \\ Discussion}

In patients with lumbosacral radicular pain allocated to either epidural steroid injections or gabapentin group, we found that although there were some small differences in favor of the injections at one month, there were no significant differences for our primary outcome measure (ODI), and the differences observed mostly disappeared at three months. Although only a small percentage of our patients had spinal stenosis, our findings are consistent with studies done in the past.

Friedly $\mathrm{JL}^{1}$, Comstock $\mathrm{BA},{ }^{\text {xix }}$ et al conducted a randomized multiocentric trial of epidural glucocorticoid injections for spinal stenosis and concluded that In the treatment of lumbar spinal stenosis, epidural injection of glucocorticoids plus lidocaine offered minimal or no short-term benefit as compared with epidural injection of lidocaine alone.

In our study epidural steroid injection were a little better than gabapentin in first month .This result is consistent with a multicentric study done by Steven P Cohen, Steven Hanling et al. They conducted multicenter randomized double blind comparative efficacy study on Epidural steroid injections compared with gabapentin for lumbosacral radicular pain and observed that among secondary outcomes, one month after treatment those who received epidural steroid injection had greater reductions in worst leg pain $(-3.0$, SD 2.8) than those treated with gabapentin $(-2.0, \mathrm{SD} 2.9 ; \mathrm{P}=0.04)$ and were more likely to experience a positive successful outcome $(66 \%$ v $46 \%$; number needed to treat $=5.0,95 \%$ confidence interval 2.8 to $27.0 ; \mathrm{P}=0.02$ ). At three months, there were no significant differences between treatments. ${ }^{\mathrm{xx}}$

\section{Conclusion}

- Both epidural steroid injections and gabapentin treatment resulted in significant improvements in Oswestry disability index.

- Although epidural steroid injections might be superior to gabapentin in some outcome measures, the differences are small and generally short lived

\section{References}

i. US Burden of Disease Collaborators. The state of US health, 1990-2010: burden of diseases, injuries, and risk factors.JAMA2013;310:591-608.

ii. Hoy D, Bain C, Williams G, et al. A systematic review of the global prevalence of low back pain. Arthritis Rheum2012;64:2028-37.

iii. Juniper M, Le T, Mladsi D. The epidemiology, economic burden, and pharmacological treatment of chronic low back pain in France, Germany, Italy, Spain and the UK: a literature-based 
review. Expert Opin Pharmacother 2009; 10:2581-92.

iv. Cohen SP, Mao J. Mechanisms of neuropathic pain and their clinical implications. . BMJ2014;348:f7656.

v. Manusov EG (September 2012). "Evaluation and diagnosis of low back pain". Prim.

Care 39 (3):

4719. doi:10.1016/j.pop.2012.06.003.PMI D 22958556.

vi. Cohen SP, Argoff CE, Carragee EJ (2008). "Management of low back pain". BMJ337: a2718. doi:10.1136/bmj.a2718. PMID 191 03627

vii. Koes, BW; van Tulder, M; Lin, CW; Macedo, LG; McAuley, J; Maher, C (December 2010). "An updated overview of clinical guidelines for the management of non-specific low back pain in primary care.". European Spine Journal 19 (12): 2075-94.doi:10.1007/s00586-010-1502y. PMID 20602122

viii. Manchikanti L, Falco FJ, Singh V, et al. Utilization of interventional techniques in managing chronic pain in the Medicare population: analysis of growth patterns from 2000 to 2011. Pain Physician2012;15:E969-82.

ix. Cohen SP, Jamison D, Bicket M, et al. Epidural steroids: a comprehensive, evidence-based review. Reg Anesth Pain Med2013;38:175-200

x. Hopwood M, Abram S. Factors associated with failure of lumbar steroids. Reg Anes1993;18:238-43

xi. Romano CL, Romanò D, Bonora C, et al Pregabalin, celecoxib, and their combination for treatment of chronic low- back pain. J Orthopaed Traumatol 2009; 10(4):185-91.

xii. Baron R, Martin-Mola E, Müller M, et al. Effectiveness and safety of tapentadol prolonged release (PR) versus a combination of tapentadol PR and gabapentinfor the management of severe, chronic low back pain with a neuropathic component: a randomized, double-blind, phase $3 b \quad$ study. Pain Pract2014;doi:10.1111/papr.12200

xiii. Baron R, Freynhagen R, Tölle TR, et al; A0081007 Investigators. The efficacy and safety of gabapentinin the treatment of neuropathic pain associated with chronic lumbosacral radiculopathy. Pain2010;150:420-7.

xiv. Pinto RZ, Maher CG, Ferreira ML, et al. Epidural corticosteroid injections in the management of sciatica: a systematic review and meta-analysis. Ann Intern Med2012;157:865-77.

xv. Brouwers MC, Thabane L, Moher D, et al. Comparative effectiveness research paradigm: implications for systematic reviews and clinical practice guidelines. $\mathbf{J}$ Clin Oncol2012;30:4202-7

xvi. Laiq N, Khan MN, Iqbal MJ, et al. Comparison of epidural steroid injections with conservative management in patients with lumbar radiculopathy. J Coll Physicians Surg Pak2009;19:539-43

xvii. Dincer U, Kiralp MZ, Cakar E, et al. Caudal epidural injection versus nonsteroidal anti-inflammatory drugs in the treatment of low back pain accompanied 
with radicular pain. Joint Bone Spine2007;74:467-71

xviii. Cohen SP, Hayek S, Semenov Y, et al. Epidural steroid injections, conservative treatment or combination treatment for cervical radiculopathy: a multi-center, randomized, comparative-effectiveness study. Anesthesiology2014;121:1045-55.

xix. Friedly JL, Comstock BA, Turner JA, Heagerty PJ, Deyo RA, Sullivan $\mathrm{SD}$,et al. A randomized trial of epidural glucocorticoid injections for spinal stenosis. N Engl J Med2014;371:11-21.

xx. Steven P Cohen, Steven Hanling, Mark C Bicket, Ronald L White, Elias Veizi, Connie Kurihara et al. Epidural steroid injections compared with gabapentin for lumbosacral radicular pain: multicenter randomized double blind comparative efficacy study . BMJ 2015;350:h1748 